\title{
The effect of milling additives on powder properties and sintered body microstructure of $\mathrm{NiO}$
}

\author{
L. Jay DEINER ${ }^{a,{ }^{*}}$, Michael A. ROTTMAYER ${ }^{b}$, Bryan C. EIGENBRODT $^{c}$ \\ ${ }^{a}$ Department of Chemistry, New York City College of Technology, City University of New York, \\ 300 Jay St., Brooklyn, NY 11201, USA \\ ${ }^{b}$ The Air Force Research Labs, Wright-Patterson Air Force Base, OH 45433, USA \\ ${ }^{c}$ Department of Chemistry, Villanova University, 800 E. Lancaster Ave., Villanova, PA 19085, USA
}

Received: December 15, 2014; Revised: February 26, 2015; Accepted: February 27, 2015

(C) The Author(s) 2015. This article is published with open access at Springerlink.com

\begin{abstract}
The evolution of powder particle size, crystal structure, and surface chemistry was evaluated for micron scale $\mathrm{NiO}$ powders subjected to impact milling with commonly employed milling additives: methanol, Vertrel XF, and amorphous carbon. The effect of the different comminution protocols on sintered body microstructure was evaluated for high temperature sintering in inert atmosphere $\left(\mathrm{N}_{2}\right)$. $\mathrm{X}$-ray photoelectron spectroscopy showed that $\mathrm{NiO}$ powder surface chemistry is surprisingly sensitive to milling additive choice. In particular, the proportion of powder surface defect sites varied with additive, and methanol left an alcohol or alkoxy residue even after drying. Upon sintering to intermediate temperatures $\left(1100{ }^{\circ} \mathrm{C}\right)$, scanning electron microscopy (SEM) showed that slurry milled $\mathrm{NiO}$ powders exhibit hindered sintering behaviors. This effect was amplified for $\mathrm{NiO}$ milled with methanol, in which sub-500 nm grain sizes dominated even after sintering to $1100{ }^{\circ} \mathrm{C}$. Upon heating to high temperatures $\left(1500{ }^{\circ} \mathrm{C}\right)$, simultaneous differential scanning calorimetry/thermogravimetric analysis (DSC/TGA) showed that the powders containing carbon residues undergo carbothermal reduction, resulting in a melting transition between 1425 and $1454{ }^{\circ} \mathrm{C}$. Taken together, the results demonstrated that when processing metal oxide powders for advanced ceramics, the choice of milling additive is crucial as it exerts significant control over sintered body microstructure.
\end{abstract}

Keywords: nickel oxide; impact milling; sintering; densification; grain growth

\section{Introduction}

Nickel oxide is a catalytically important material, especially in the context of emerging energy technologies like solid oxide fuel cells $[1,2]$. In these devices, the microstructure of the sintered $\mathrm{NiO} / \mathrm{YSZ}$ cermet anode strongly affects the solid oxide fuel cell performance [3-5]. Specific attempts at controlling

* Corresponding author.

E-mail: Ldeiner@citytech.cuny.edu
$\mathrm{NiO} / \mathrm{YSZ}$ cermet microstructure have focused on starting catalyst powder particle sizes [6], the ratio between $\mathrm{NiO}$ and YSZ content [7,8], and processing techniques including mechanical alloying through milling [9-12]. Nonetheless, there remain challenges to achieving an ideal anode structure, especially in the area of controlling grain growth and densification of the $\mathrm{NiO}$ component during high temperature sintering $\left(>1000{ }^{\circ} \mathrm{C}\right)$. In principle, such growth could be controlled by tuning the physical (particle shape, size, size distribution, and extent of agglomeration $[13,14]$ ), 
chemical (grain boundary chemistry [15], oxide impurities [16], and surface segregating dopants [17]), and electronic (surface oxidation state [18]) characteristics of the starting $\mathrm{NiO}$ powders. Continued development of synthetic and/or processing techniques for tuning the characteristics of $\mathrm{NiO}$ powders is thus necessary.

For the purpose of engineering nanoscale and micron scale powders, "bottom up" synthetic methods exhibit excellent structure/property control [19], but "top down" methods like high energy milling may be a more cost effective way to create large volumes of powders whose properties have been tuned to optimize sintered body microstructure. Variations in milling time and processing conditions provide the ability to control powder particle size, size distribution, particle shape, defect density, oxidation state, and surface chemistry [20-23]. In the present work, we investigate the use of three milling additives (amorphous carbon, methanol, and Vertrel XF) for tuning the particle size, particle size distribution, surface chemistry, and surface oxidation state of $\mathrm{NiO}$ powders. We correlate these powder properties with the microstructure of sintered NiO compacts and with the energetics of sintering. Previous work has shown that the presence of residues from processing additives hinders sintering in some cases [24] and facilitates sintering in others [25]. By correlating how additive-driven changes in the chemical and physical structures of the powders affect sintered body microstructure, this work aims to provide principles for choosing milling additives for large scale production of $\mathrm{NiO}$ powders engineered to produce sintered parts with controlled microstructures.

\section{Materials and methods}

The starting $\mathrm{NiO}$ material (Nickelous Oxide, Green, Powder, Baker Analyzed Reagent for Electronic Ceramics, Avantor Performance Materials, Center Valley, PA) was subjected to high energy ball milling using a SPEX 8000M Mixer/Mill (SPEX Sample Prep, Metuchen, NJ). All milling experiments were conducted in a zirconia vessel with two $12.7 \mathrm{~mm}$ spherical zirconia beads employed as milling media. The total milling time per sample was $480 \mathrm{~min}$. As described in Table 1, the $\mathrm{NiO}$ samples were dry milled with an amorphous carbon additive or slurry milled with either methanol or Vertrel XF $(1,1,1,2,2,3,4,5,5,5$ -decafluoropentane). For reference, NiO milled
Table 1 Summary of the samples and milling conditions employed for grinding $\mathrm{NiO}$

\begin{tabular}{cl}
\hline Sample & \multicolumn{1}{c}{ Additive } \\
\hline $\mathrm{NiO}$ & None \\
$\mathrm{NiO} / \mathrm{C}(1.5 \%)$ & Printex L amorphous carbon, 1.5 wt $\%$ \\
$\mathrm{NiO} /$ methanol & Methanol (Sigma Aldrich, Anhydrous, 99.8\%) \\
$\mathrm{NiO} /$ Vertrel & Vertrel XF (1,1,1,2,2,3,4,5,5,5-decafluoropentane, \\
& DuPont) \\
\hline
\end{tabular}

with no additive was also included. In all milling experiments, the total mass of powders was $10 \mathrm{~g}$. The powders milled with amorphous carbon contained $1.5 \mathrm{wt} \%$ carbon. For slurry milling, $\sim 11 \mathrm{~mL}$ of liquid was added to the $10 \mathrm{~g}$ of $\mathrm{NiO}$. The liquid was refilled every $90 \mathrm{~min}$ to compensate for evaporation.

The Brunauer-Emmett-Teller (BET) surface areas of the powders before and after milling were obtained with an ASAP 2020 Physisorption Analyzer (Micromeritics). The particle morphologies and approximate size distributions were analyzed before and after milling using scanning electron microscopy (SEM; Amray 1910, FE-SEM). Prior to SEM imaging, the powder samples were sputtered with $2 \mathrm{~nm}$ of $\mathrm{Au} / \mathrm{Pd}$ (EMS 150RS, Electron Microscopy Sciences). Before and after milling, crystal structure was obtained via X-ray diffraction (Bruker, D8). Insight into the $\mathrm{NiO}$ surface oxidation state and presence of chemisorbed species before and after milling was obtained using X-ray photoelectron spectroscopy of the powder samples (Surface Science Instruments M-Probe, Service Physics, Inc.). A monochromatic $\mathrm{Al} \mathrm{Ka}$ filament $(1486.6 \mathrm{eV})$ was employed, and the emission current and operating voltage were fixed at $20 \mathrm{~mA}$ and $10 \mathrm{kV}$, respectively. All X-ray photoelectron spectroscopy data were shown after Shirley baseline correction. In accord with the literature, the binding energies were corrected for charging using the $\mathrm{O} 1 \mathrm{~s}$ peak of bulk $\mathrm{NiO}$ at $529.5 \mathrm{eV}$ as an internal calibration standard [26]. As a check of this binding energy correction method, we compared the binding energy values derived using the $\mathrm{O} 1 \mathrm{~s}$ internal calibration method to those obtained by correcting for charging using the adventitious carbon peak at $284.5 \mathrm{eV}[27,28]$. To within the limits of $\pm 0.2 \mathrm{eV}$, both methods of correction for charging led to consistent peak values in $\mathrm{X}$-ray photoelectron spectroscopy.

The milled powders were pressed into pellets using a Carver press (Carver, Inc.) employing a pressure of $10000 \mathrm{psi}$ for $5 \mathrm{~min}$. The diameter of the die was $12.7 \mathrm{~mm}$, and the mass of $\mathrm{NiO}$ used per pellet was $0.75 \mathrm{~g}$. No organic binder was added during powder 
compaction. The resulting green pellet height was $1.61 \mathrm{~mm}$. The pellets were then subjected to sintering in $\mathrm{N}_{2}$ using a reducing furnace. The heating ramp was $1{ }^{\circ} \mathrm{C} / \mathrm{min}$ to the maximum dwell temperature of either 1100 or $1500{ }^{\circ} \mathrm{C}$. The samples were held for $4 \mathrm{~h}$ at the maximum dwell temperature, then cooled at a rate of $5{ }^{\circ} \mathrm{C} / \mathrm{min}$. After sintering, the pellets were cleaved and analyzed in cross section with SEM (JSM 6060, Joel). Sample porosities were determined from the cross sectional images using the SEM software.

Simultaneous differential scanning calorimetry/ thermogravimetric analysis (DSC/TGA) measurements were performed with a TA Instruments SDT Q600 instrument. The measurements were performed by loading $20-45 \mathrm{mg}$ of the $\mathrm{NiO}$ powders into an alumina sample pan. All measurements were performed under flowing nitrogen (Airgas, High Purity, 4.8 grade). The rate of flow was $100 \mathrm{~mL} / \mathrm{min}$. The temperature was stabilized at $40{ }^{\circ} \mathrm{C}$ for $10 \mathrm{~min}$ before ramping at a rate of $10{ }^{\circ} \mathrm{C} / \mathrm{min}$ to a maximum temperature of $1500{ }^{\circ} \mathrm{C}$. The samples were held at the maximum temperature for $30 \mathrm{~min}$. Weight change and heat flow were measured during the temperature ramp and during the dwell time at the maximum temperature. In order to establish the reversibility of heat flow events for the $\mathrm{NiO} / \mathrm{C}$ and $\mathrm{NiO} /$ methanol samples, additional experiments were performed in which the temperature was stabilized at $40{ }^{\circ} \mathrm{C}$ for $10 \mathrm{mim}$ before ramping at a rate of $10{ }^{\circ} \mathrm{C} / \mathrm{min}$ to a maximum temperature of $1500{ }^{\circ} \mathrm{C}$. The samples were then cooled at a rate of $10{ }^{\circ} \mathrm{C} / \mathrm{min}$ down to a final temperature of $300{ }^{\circ} \mathrm{C}$. For all experiments, the heat flow was normalized by the real time sample weight and was presented as a weight corrected heat flow.

\section{Results and discussion}

\section{1 Powder characterizations}

The BET surface areas and corresponding average particle diameters are shown in Table 2 for all milling procedures. The average particle diameters were estimated from the BET surface areas using Eq. (1) [29]:

$$
D_{\mathrm{BET}}=6 /\left(\rho \times S_{\mathrm{BET}}\right)
$$

where $D_{\mathrm{BET}}$ is the particle diameter estimated from BET; $\rho$ is the powder density; and $S_{\mathrm{BET}}$ is the BET surface area. As seen in Table 2, the BET surface area
Table 2 BET surface areas and estimated particle sizes of $\mathrm{NiO}$ powders before and after $480 \mathrm{~min}$ of milling

\begin{tabular}{cccc}
\hline Sample & $\begin{array}{c}\text { Milling } \\
\text { time }(\min )\end{array}$ & $\begin{array}{c}\text { BET surface } \\
\text { area }\left(\mathrm{m}^{2} / \mathrm{g}\right)\end{array}$ & $\begin{array}{c}\text { BET average } \\
\text { particle size }(\mathrm{nm})\end{array}$ \\
\hline $\mathrm{NiO}$ & 0 & 3.5 & 255 \\
$\mathrm{NiO}$ & 480 & 12.4 & 72 \\
$\mathrm{NiO} / \mathrm{C}(1.5 \%)$ & 480 & 16.8 & 54 \\
$\mathrm{NiO} /$ methanol & 480 & 4.6 & 198 \\
$\mathrm{NiO} /$ Vertrel & 480 & 4.9 & 183 \\
\hline
\end{tabular}

of the as-received $\mathrm{NiO}$ powders was $\sim 3.5 \mathrm{~m}^{2} / \mathrm{g}$. After 480 min of milling, all of the dry milled samples have BET surface areas $>10 \mathrm{~m}^{2} / \mathrm{g}$. In contrast, the powders that were slurry milled in Vertrel XF and methanol exhibit more modest BET surface area increases to $\sim 4.9$ and $4.6 \mathrm{~m}^{2} / \mathrm{g}$, respectively. The observation of a more rapid decrease in particle size for dry versus wet grinding is consistent with previous work, documenting structural changes of $\alpha-\mathrm{Fe}_{2} \mathrm{O}_{3}$ as a function of milling environment [30]. In contrast, a more rapid decrease in particle size is observed for slurry milling of $\mathrm{ZrO}_{2}$ as opposed to dry milling [31]. This apparent inconsistency is resolved when we consider that the zirconia study measured particle size using sedimentation. As such, agglomerates and primary particles are indistinguishable. It is expected that the dry milled samples of $\mathrm{ZrO}_{2}$ contain smaller primary particles, but they are more heavily aggregated as compared to the corresponding slurry milled samples.

From Table 2, it is also clear that the surface area of the $\mathrm{NiO}$ dry milled with carbon is greater than $\mathrm{NiO}$ dry milled with no additive. If the BET surface area of $\mathrm{NiO}$ milled with carbon is estimated to be a weighted average of the BET surface areas of the starting Printex $\mathrm{L}$ carbon material $\left(150 \mathrm{~m}^{2} / \mathrm{g}\right)$ and $\mathrm{NiO}$ milled alone, the estimated value is $14.5 \mathrm{~m}^{2} / \mathrm{g}$, still less than the measured value shown in Table 2. As such, it is probable that the carbon acts as a grinding aid for $\mathrm{NiO}$ $[32,33]$ while itself undergoing comminution during milling.

The SEM images of the powders provide insight into the particle size distributions of the milled samples (Fig. 1). The unmilled powders (Fig. 1(a)) are characterized by aggregated and irregular $\mathrm{NiO}$ particles, with few particles below $200 \mathrm{~nm}$ in size. After milling for $480 \mathrm{~min}$ with no additive (Fig. 1(b)), the extent of aggregation increases while the particle size distribution now includes many more particles in the $100 \mathrm{~nm}$ range. Milling for $480 \mathrm{~min}$ with carbon (Fig. 1(c)) also increases the frequency of small 
$(<100 \mathrm{~nm})$ particles. Slurry milling in Vertrel XF (Fig. 1(d)) produces a more homogeneous particle size distribution with few particles less than $100 \mathrm{~nm}$. Similarly, slurry milling in methanol produces a particle size distribution with few particles below $100 \mathrm{~nm}$. These qualitative results support the BET surface area measurements which indicate only modest surface area increases with slurry milling.

Upon dry milling, the color of the $\mathrm{NiO}$ samples shifts from green to dark brown. Since stoichiometric $\mathrm{NiO}$ is bright green and non-stoichiometric $\mathrm{Ni}_{x} \mathrm{O}_{y}$ is dark brown [34], it is suspected that dry milling either changes the bulk crystal structure of the $\mathrm{NiO}$ or changes the surface chemistry of the NiO. The former possibility can be excluded because X-ray diffraction does not provide any evidence for a change in bulk crystal structure upon milling for $480 \mathrm{~min}$ with or without additives (Fig. 2). All of the peaks present in the X-ray diffraction spectra of $\mathrm{NiO}$ milled for $480 \mathrm{~min}$ are in the same location as the peaks for unmilled NiO. These peaks are consistent with reported X-ray diffraction patterns for $\mathrm{NiO}$, indicating that milling does not induce changes to the crystal structure of the bulk materials [35]. Peak broadening is observed for dry milled $\mathrm{NiO}$, but not for the slurry milled $\mathrm{NiO}$ (Fig. 2). This broadening is attributed primarily to
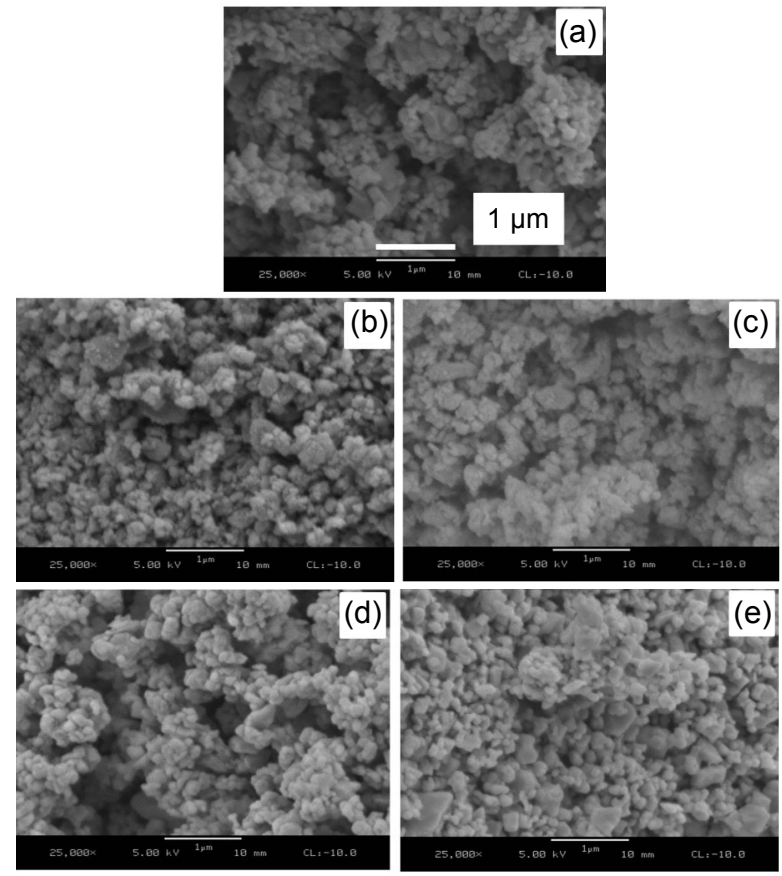

Fig. 1 SEM images of $\mathrm{NiO}$ powders after: (a) no milling; (b) 480 min of milling with no additive; (c) 480 min of milling with $1.5 \%$ Printex L carbon; (d) $480 \mathrm{~min}$ of milling with Vertrel XF; and (e) $480 \mathrm{~min}$ of milling with methanol.

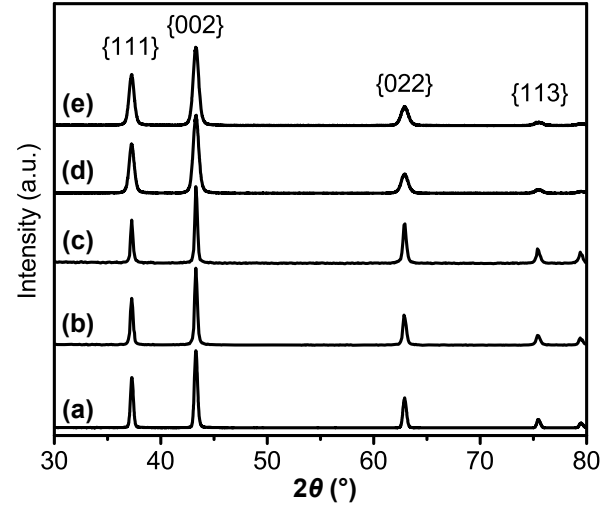

Fig. 2 X-ray diffraction data for: (a) unmilled NiO; (b) $\mathrm{NiO}$ slurry milled in methanol; (c) $\mathrm{NiO}$ slurry milled in Vertrel; (d) dry milled NiO; and (e) NiO dry milled with carbon.

crystallite size reduction with possible contributions from milling induced strain [35]. This interpretation is consistent with the fact that significant particle size reduction is observed in BET for dry milled $\mathrm{NiO}$, but not for slurry milled NiO.

While X-ray diffraction measurements indicate that milling does not change the bulk crystal structure of $\mathrm{NiO}, \mathrm{X}$-ray photoelectron spectroscopy provides clear evidence for milling-induced chemical modification of the NiO powder surface. The $\mathrm{Ni} 2 \mathrm{p} 3 / 2$ region of the unmilled NiO (Fig. 3(a)) displays a multiplet which is fitted by two peaks centered at 853.8 and $855.4 \mathrm{eV}$. It also displays a shake-up feature fit by peaks centered at 860.7 and $863.6 \mathrm{eV}$. The peak locations and peak widths are consistent with the literature reports for $\mathrm{NiO}$ [27,36]. In the milled $\mathrm{NiO}$ samples, the $\mathrm{Ni} 2 \mathrm{p} 3 / 2$ region displays subtle differences in the extent to which the multiplet splitting peaks are resolved. This is consistent with changes to the $\mathrm{NiO}$ surface either through modification of the $\mathrm{Ni}^{2+} / \mathrm{Ni}^{3+}$ ratio or through the presence of adsorbates [26,37].

The origin of the chemical modifications to the $\mathrm{NiO}$ surface can be further understood by examination of the $\mathrm{O} 1 \mathrm{~s}$ region of the X-ray photoelectron spectroscopy data (Fig. 3(b) and Table 3). Unmilled $\mathrm{NiO}$ displays two peaks, one at $529.4 \mathrm{eV}$ (full width at half maximum $(\mathrm{FWHM})=1.2 \mathrm{eV}$ ) and the other at $531.0 \mathrm{eV}(\mathrm{FWHM}=2.3 \mathrm{eV})$ (Fig. 3(b)(i)). These peaks are frequently observed for $\mathrm{NiO}$. The $529.4 \mathrm{eV}$ is assigned to oxygen in the $\mathrm{NiO}$ lattice $[27,36]$. In previous works, the $531.0 \mathrm{eV}$ has been ascribed either to oxygen from hydroxyl or to other oxygen-containing moieties, most likely adsorbed at defect sites $[38,39]$. It has recently been shown that the $531.0 \mathrm{eV}$ peak can 

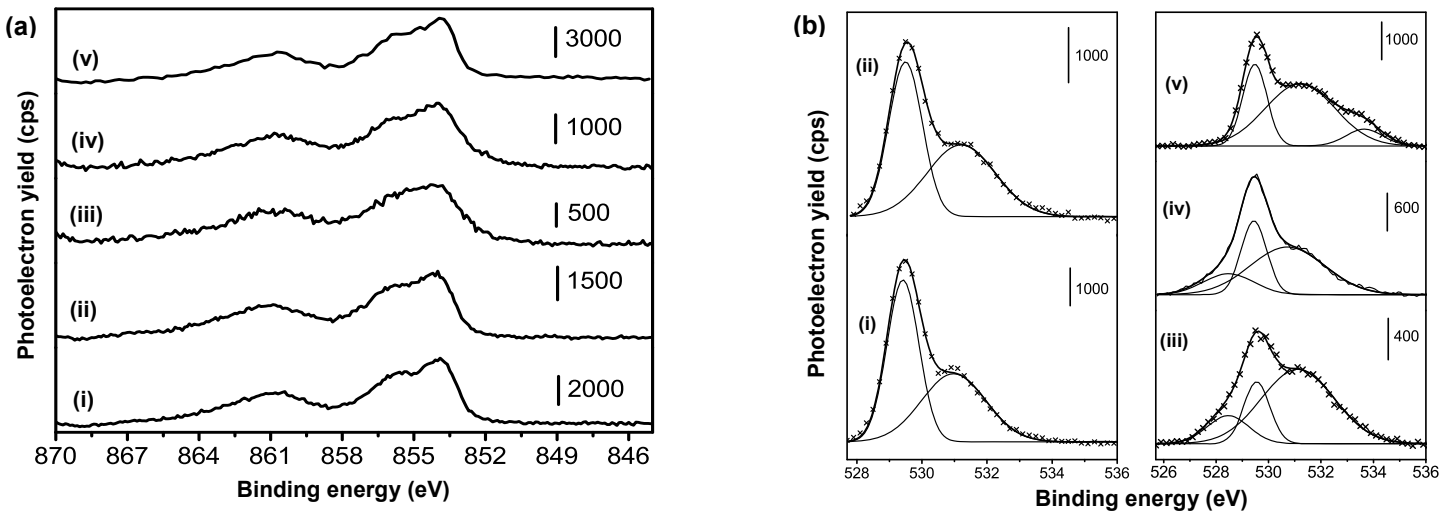

Fig. 3 X-ray photoelectron spectroscopy data for the (a) Ni 2p3/2 region and (b) O 1s region of: (i) unmilled $\mathrm{NiO}$; (ii) $\mathrm{NiO}$ milled for 480 min with no additive; (iii) $\mathrm{NiO}$ milled for $480 \mathrm{~min}$ with carbon Printex L; (iv) NiO milled for 480 min with Vertrel XF; and (v) NiO milled for 480 min with methanol.

Table 3 Peak fits for the $\mathrm{O}$ 1s region of X-ray photoelectron spectroscopy data for NiO before and after undergoing high energy milling treatments

\begin{tabular}{cccccc}
\hline & Unmilled NiO NiO milled with no additive NiO milled with Printex carbon & NiO milled with Vertrel & NiO milled with methanol \\
\hline Binding energy (eV) & 529.4 & 529.5 & 529.5 & 529.4 & 529.4 \\
FWHM (eV) & 1.2 & 1.2 & 1.2 & 1.2 & 1.1 \\
Assignment & Lattice oxygen & Lattice oxygen & Lattice oxygen & Lattice oxygen & Lattice oxygen \\
\hline Binding energy (eV) & 531.0 & 531.2 & 531.1 & 530.7 & 531.2 \\
FWHM (eV) & 2.3 & 2.5 & 2.8 & 2.8 & 3.1 \\
Assignment & Defect oxygen & Defect oxygen & Defect oxygen & Defect oxygen & Defect oxygen, alkoxy, OH \\
\hline Binding energy (eV) & & 528.5 & 528.5 & \\
FWHM (eV) & & 1.9 & 2.2 & \\
Assignment & & Non-equilibrium oxygen & Non-equilibrium oxygen & \\
Binding energy (eV) & & & 533.5 \\
FWHM (eV) & & & & 1.6 \\
Assignment & & & & Alcohol \\
\hline
\end{tabular}

also be observed in the absence of adsorbed oxygen containing species, suggesting that it can be associated with the defect sites themselves [27,40]. In our unmilled $\mathrm{NiO}$ sample, the ratio between the area of the lattice oxygen peak and the $531.0 \mathrm{eV}$ oxygen peak is 1.2:1. After the NiO is milled with no additive, the same two $O$ 1s peaks are present, but the ratio of the lattice oxygen to the $531.0 \mathrm{eV}$ oxygen peak is $1: 1.1$, indicating an increase in defect or adsorbate sites upon milling (Fig. 3(b)(ii)). When $\mathrm{NiO}$ is dry milled in the presence of carbon, the shape of the $\mathrm{O}$ 1s peak changes such that it can no longer be fitted solely by the states used to describe unmilled NiO. The peak at $531.1 \mathrm{eV}$ has a larger FWHM $(2.8 \mathrm{eV})$ as compared to the unmilled $\mathrm{NiO}$ and the $\mathrm{NiO}$ milled without any additive. This is likely due to a greater variety of defect sites arising on the particles milled with carbon. In addition, there is a new low binding energy feature centered at $528.5 \mathrm{eV}(\mathrm{FWHM}=1.9 \mathrm{eV})$. This peak has been observed previously for the early stages of solution processed $\mathrm{NiO}$ film growth [41] and $\mathrm{AgO}$ film growth [42]. In both cases, it is ascribed to a transient oxygen feature associated with oxygen bonded to partially reduced $\mathrm{Ni}$. The $\mathrm{O} 1 \mathrm{~s}$ region of $\mathrm{NiO}$ milled with Vertrel displays the same three states as $\mathrm{NiO}$ milled with carbon. However, the ratios of the integrated areas of these peaks differ. For $\mathrm{NiO}$ milled in carbon, the ratio of the integrated areas of the $528.5 \mathrm{eV}$ peak to that of the $529.5 \mathrm{eV}$ peak and $531 \mathrm{eV}$ peak is 1:1.4:4.6. For NiO milled in Vertrel, the corresponding ratio is 1:1.8:3.4. This difference is consistent with the BET data that indicates that carbon acts as a milling aid, cleaving $\mathrm{NiO}$ at a more rapid rate and creating a larger number of surface defects. Finally, the $\mathrm{O} 1 \mathrm{~s}$ region of $\mathrm{NiO}$ milled in methanol shows three peaks centered at $529.5,531.2$, and $533.7 \mathrm{eV}$. The peak at $529.5 \mathrm{eV}$ is ascribed to the lattice oxygen of $\mathrm{NiO}$, and the peak at $533.7 \mathrm{eV}$ is ascribed to the intact alcohol $[43,44]$. While the peak at $531.2 \mathrm{eV}$ is primarily associated with surface defects as described above, it may also contain contributions from the dissociation of methanol to alkoxide and $\mathrm{OH}$. Support for the presence of alkoxide and $\mathrm{OH}$ is provided by the increased FWHM $(3.1 \mathrm{eV})$ and high integrated area of the $531.2 \mathrm{eV}$ peak, almost 
twice as large as the 529.5 peak. Since the BET data indicate that the extent of comminution of $\mathrm{NiO}$ in methanol is not that high, it seems likely that for $\mathrm{NiO}$ milled in methanol, the $531.2 \mathrm{eV}$ peak is not solely composed of contributions from defect sites. The presence of $\mathrm{C}-\mathrm{H}$ stretching peaks in diffuse reflectance infrared spectroscopy of the methanol milled $\mathrm{NiO}$ (data not shown) provides support for the hypothesis that alcohol and/or alkoxide moieties are present on the surface of $\mathrm{NiO}$ milled with methanol.

\section{2 Scanning electron microscopy and thermal analyses of sintering}

SEM images of sintered pellets from milled and unmilled $\mathrm{NiO}$ show significant differences in microstructure as a function of milling additives (Fig. 4). For intermediate temperature sintering $\left(1100{ }^{\circ} \mathrm{C}\right)$ (Fig. 4(a)), the unmilled $\mathrm{NiO}$ sample shows notable but inhomogeneous particle size growth with some sub-micron particles remaining, but significant fusion of particles into grains greater than two microns. The porosity of the unmilled $\mathrm{NiO}$ sample sintered to $1100{ }^{\circ} \mathrm{C}$ is $1.6 \%$. The sample milled with carbon undergoes an accelerated grain growth, maintaining almost no sub-micron particles and achieving a porosity of $1.7 \%$, nearly the same as that of the unmilled $\mathrm{NiO}$ sample. In contrast, both of the slurry milled samples ( $\mathrm{NiO} /$ Vertrel and $\mathrm{NiO} /$ methanol) display a hindered particle size growth maintaining smaller, more homogeneous particle sizes, and higher porosities of $2.3 \%$. The combination of hindered particle size growth and higher porosity suggests that, after sintering to intermediate temperatures, the slurry milled samples bear a closer resemblance to unsintered pressed powder compact as compared to the dry milled or unmilled samples. Notably, for $\mathrm{NiO}$ milled in methanol, sintering to $1100{ }^{\circ} \mathrm{C}$ results in minimal particle size growth with almost all particles maintaining sizes below $500 \mathrm{~nm}$. Despite this hindered particle size growth, for both $\mathrm{NiO} /$ methanol and $\mathrm{NiO} /$ Vertrel, there are regions where the small particles have fused together resulting in amorphous regions with indistinct grain boundaries. Finally, we note that preliminary investigations of $\mathrm{NiO}$ milled with no additive produce a structure with inhomogeneous pores and large irregular grains. Because of the non-optimal characteristics of this microstructure, we elected not to carry it forward in the future studies.

Differences in porosity and grain growth persist (a)
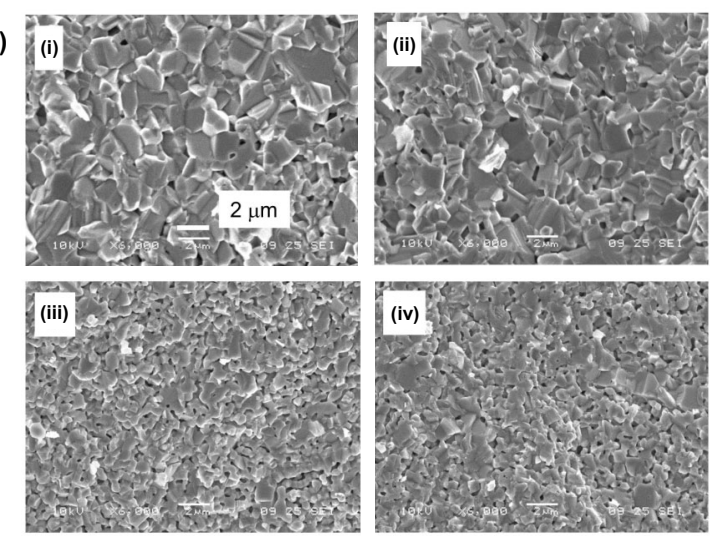

(b)
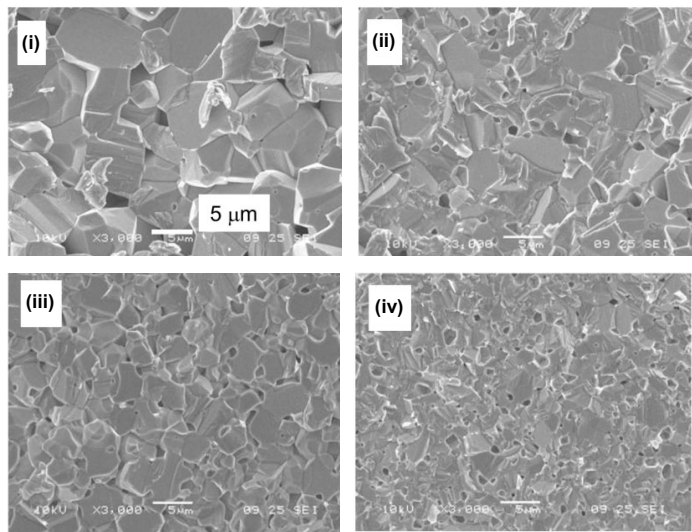

Fig. 4 SEM images of $\mathrm{NiO}$ powders sintered in $\mathrm{N}_{2}$ to (a) $1100{ }^{\circ} \mathrm{C}$ and (b) $1500{ }^{\circ} \mathrm{C}$. Powders are: (i) $\mathrm{NiO}$ unmilled; (ii) $\mathrm{NiO}$ milled for 480 min with carbon; (iii) $\mathrm{NiO}$ milled for 480 min with methanol; and (iv) $\mathrm{NiO}$ milled for 480 min with Vertrel XF.

even when the $\mathrm{NiO}$ is sintered to $1500{ }^{\circ} \mathrm{C}$ (Fig. 4(b)), well into the range of final stage sintering [45]. After the $1500{ }^{\circ} \mathrm{C}$ sintering treatment, the unmilled $\mathrm{NiO}$ has grains in the range of 5 microns and above, with distinct grain boundaries and an open structure of micron scale pores. Between 1100 and $1500{ }^{\circ} \mathrm{C}$, total porosity of this sample decreases only slightly to a final value of $1.3 \%$. NiO sample dry milled with carbon has almost no discernible grains and isolated pores ranging from nanoscale to micron scale. During the final stage of sintering, the total porosity decreases to $0.8 \%$, a much more pronounced decrease than that seen for the unmilled sample. After sintering to $1500{ }^{\circ} \mathrm{C}$, NiO milled with methanol displays irregular particles ranging from 1 to 5 microns and pores ranging from less than 1-2 microns. As in the case of $\mathrm{NiO}$ milled with carbon, the porosity decreases noticeably to a final value of $1.4 \%$. NiO milled in Vertrel has no discernible grains and a large number of isolated pores ranging in size from sub-micron to 2 
microns. Similar to unmilled $\mathrm{NiO}$, the porosity of $\mathrm{NiO}$ milled with Vertrel decreases only modestly between 1100 and $1500{ }^{\circ} \mathrm{C}$ (two tenths of a percent), resulting in a final porosity of $2.1 \%$.

Simultaneous DSC/TGA confirms the presence of milling additive residues and shows their effects on heat flow during sintering (Fig. 5). In the thermogravimetric analysis trace (Fig. 5(a)), NiO milled with $1.5 \mathrm{wt} \%$ carbon shows the most pronounced mass loss, $5.1 \%$, upon heating. The majority of mass is lost between 513 and $800{ }^{\circ} \mathrm{C}$ in a distinct two-step process. This two-step pattern of mass loss has been observed previously for $\mathrm{NiO}-\mathrm{YSZ}$, and has been attributed to the carbothermal reduction of $\mathrm{NiO}$ [46]. In this process, carbon abstracts surface oxygen and desorbs from the surface as represented by overall Eqs. (2) and (3):

$$
\mathrm{C}(\text { ads })+2 \mathrm{O}(\text { ads }) \rightarrow \mathrm{CO}_{2}(\mathrm{~g})
$$
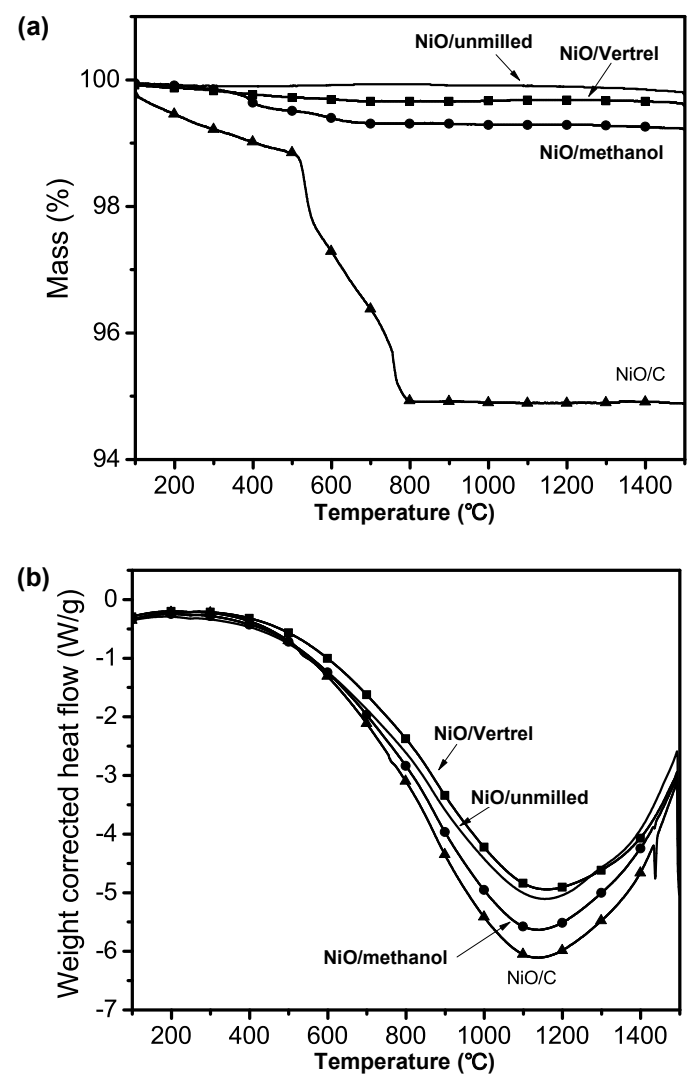

Fig. 5 (a) Thermogravimetric analysis and (b) differential scanning calorimetry for unmilled $\mathrm{NiO}$ (black line), $\mathrm{NiO}$ milled with carbon (black line + triangle symbols), $\mathrm{NiO}$ milled with methanol (black line + circle symbols), and $\mathrm{NiO}$ milled with Vertrel XF (black line + square symbols). In the differential scanning calorimetry traces, exothermic events produce an upward peak.

$$
\mathrm{C}(\text { ads })+\mathrm{O}(\text { ads }) \rightarrow \mathrm{CO}(\mathrm{g})
$$

If $1.5 \mathrm{wt} \%$ carbon were to desorb fully by combination to $\mathrm{CO}_{2}$ (Eq. (2)), a total mass loss of $5.5 \%$ would be expected. The observed mass loss of 5.1\% suggests that $80 \%$ of the carbon desorbs as $\mathrm{CO}_{2}$ and $20 \%$ desorbs as CO. These desorption events are endothermic as observed by the downward peaks at 536 and $761{ }^{\circ} \mathrm{C}$ in the weight corrected heat flow recorded during differential scanning calorimetry (Fig. 5(b)). These endothermic events are most obvious in the first derivative of the weight corrected heat flow (Fig. 6(a)).

Since the present thermal experiments take place under flowing $\mathrm{N}_{2}(\mathrm{~g})$, the only source of oxygen for the
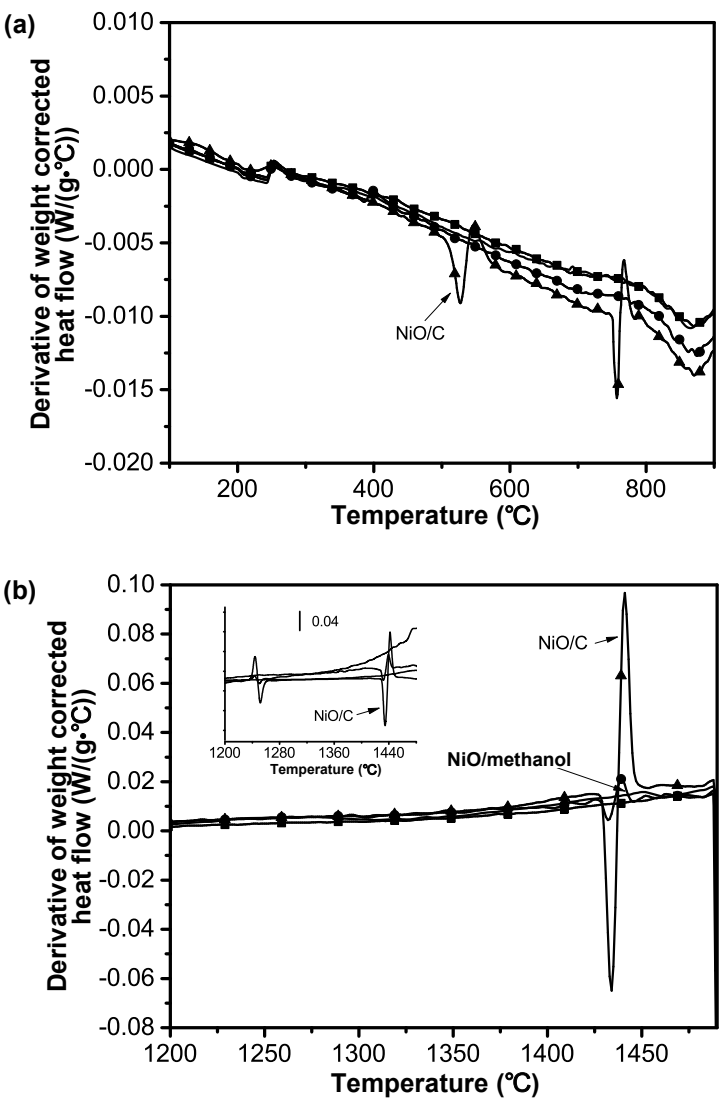

Fig. 6 Temperature derivative of the weight corrected heat flow from differential scanning calorimetry measurements of unmilled $\mathrm{NiO}$ (black line), $\mathrm{NiO}$ milled with carbon (black line + triangle symbols), $\mathrm{NiO}$ milled with methanol (black line + circle symbols), and $\mathrm{NiO}$ milled with Vertrel XF (black line + square symbols) for the temperature ranges of (a) $100-900{ }^{\circ} \mathrm{C}$ and (b) $1200-1500{ }^{\circ} \mathrm{C}$. Inset in (b): derivative of the weight corrected heat flow for $\mathrm{NiO} / \mathrm{C}$ and $\mathrm{NiO} /$ methanol (as labeled) in both the forward and reverse scans. The $\mathrm{NiO} /$ methanol trace has been multiplied by four in order to be visible on the same scan as the $\mathrm{NiO} / \mathrm{C}$ trace. 
combination to $\mathrm{CO}$ or $\mathrm{CO}_{2}$ is that bound to the $\mathrm{NiO}$. Thus, when carbon is used as a milling additive, the $\mathrm{NiO}$ surface is partially reduced after $800{ }^{\circ} \mathrm{C}$. As a result, a distinct endothermic melting event is observed between 1425 and $1454{ }^{\circ} \mathrm{C}$ in the differential scanning calorimetry for the $\mathrm{NiO}$ milled with $\mathrm{C}$ (Figs. 5(b) and $6(b))$. The interpretation of this event as melting is supported by its reversibility, manifested in an exothermic solidification event, observed from 1265 to $1230{ }^{\circ} \mathrm{C}$ during the cooling curve (Fig. 6 (b) inset). That the melting event is attributable to metallic or reduced $\mathrm{Ni}$ formed by $\mathrm{CO} / \mathrm{CO}_{2}$ desorption is further supported by the observation that the melting peak is not observed for the same differential scanning calorimetry experiment performed in air where oxygen is present to replenish any abstracted from the surface (data not shown). Finally, the melting point of metallic nickel is $1455{ }^{\circ} \mathrm{C}$, quite close to the temperature observed in the present study [47].

$\mathrm{NiO}$ milled with methanol shows a mass loss of $0.7 \%$ (Fig. 5(a)) indicating that the alcohol milling residue is present at the beginning of the thermogravimetric analysis experiment. This observation is in accord with the X-ray photoelectron spectroscopy data which suggests the presence of a $\mathrm{C}-\mathrm{O}$ containing species. As in the case of atomic carbon, the presence of the alcohol milling residue results in partial reduction of the $\mathrm{NiO}$ surface, and an endothermic melting transition between 1425 and $1454{ }^{\circ} \mathrm{C}$ (Figs. 5(b) and 6(b)). As in the case of $\mathrm{NiO}$ milled with carbon, this melting transition is shown to be reversible in the cooling curve (Fig. 6(b) inset). The partial surface reduction and resulting melting transition are in accord with previous studies of methanol adsorbed on NiO. In these works, upon heating, molecular desorption of the alcohol competes with surface decomposition to carbon, hydrogen, and oxygen [48]. The carbon-containing decomposition products may abstract surface oxygen upon desorption.

In contrast to $\mathrm{NiO}$ milled with amorphous carbon or methanol, the mass loss of $\mathrm{NiO}$ milled with Vertrel is significantly less $(0.3 \mathrm{wt} \%$, Fig. 5(a)) and there are no marked melting transitions or other significant endothermic or exothermic events. This suggests that Vertrel is a fairly inert milling additive that does not decompose appreciably on the $\mathrm{NiO}$ surface. This observation is in accord with the differences in the bond dissociation energies of $\mathrm{C}-\mathrm{H}(338 \mathrm{~kJ} / \mathrm{mol})$ versus C-F $(513 \mathrm{~kJ} / \mathrm{mol})$ [47].
High energy milling simultaneously influences $\mathrm{NiO}$ powder particle size distribution and surface chemistry. As such, the evolution of the powder microstructures upon sintering is a function of the concerted effects of differences in the powder particle size distributions and surface chemistries. Typically, fine powders with uniform size distributions display less rapid grain growth during intermediate stage sintering [49]. It is therefore reasonable that the relatively uniform particle size distributions of $\mathrm{NiO}$ powders milled in Vertrel and methanol result in smaller grain sizes after sintering to $1100{ }^{\circ} \mathrm{C}$ in comparison to unmilled $\mathrm{NiO}$ or $\mathrm{NiO}$ milled with carbon. These effects can be reinforced by the surface chemical differences imparted by the milling additives. Notably, it has recently been shown that the presence of surface bound $\mathrm{C}-\mathrm{OH}$ or $\mathrm{C}-\mathrm{O}-\mathrm{C}$ groups hinder surface diffusion and hence sintering of $\mathrm{TiO}_{2}$ nanoparticles [24]. In the present study, the $\mathrm{NiO}$ powders milled in methanol and shown by X-ray photoelectron spectroscopy and thermogravimetric analysis to have residual surface bound alkoxy or alcohol, display a hindered sintering behavior. The methanol milled powders sintered to $1100{ }^{\circ} \mathrm{C}$ exhibit less dramatic grain growth in comparison to the powders milled with Vertrel and carbon. However, in the present study, the mechanism of hindered sintering cannot be connected to hindered surface diffusion due to the presence of adsorbed species because thermogravimetric analysis shows that all additives desorb from the surface before $900{ }^{\circ} \mathrm{C}$. As such, the differences in the sintered microstructure are more likely to be due to the way that additives modify the surface oxidation state upon desorption. This is evident for the samples sintered to $1500{ }^{\circ} \mathrm{C}$, where carbothermal reduction by carbon and methanol decomposition products results in metallic nickel species that undergo melting by $1455{ }^{\circ} \mathrm{C}$. This melting transition is observed in differential scanning calorimetry and manifested in the extreme grain growth experienced between 1100 and $1500{ }^{\circ} \mathrm{C}$ for the powders milled in methanol and carbon. The melting transition may also be the driving force behind the significant decreases in porosity between 1100 and $1500{ }^{\circ} \mathrm{C}$, observed for the $\mathrm{NiO}$ milled with carbon and methanol. Unmilled $\mathrm{NiO}$ and $\mathrm{NiO}$ milled with an additive that does not induce carbothermal reduction (Vertrel XF) show far less pronounced decreases in porosity between 1100 and $1500{ }^{\circ} \mathrm{C}$. 


\section{Conclusions}

The choice of milling additive was shown to have a significant effect on the particle size distribution and surface chemistry of $\mathrm{NiO}$ powders. Residues from all milling additives were detectable by X-ray photoelectron spectroscopy and thermogravimetric analysis. Even though all milling additives desorbed from the powders by $900{ }^{\circ} \mathrm{C}$, NiO milled with different additives and sintered to 1100 and $1500{ }^{\circ} \mathrm{C}$ displayed microstructural differences. Some of these differences may be due to the effects of the milling additives on the particle size distributions of the powders. However, the presence of distinct melting transitions for $\mathrm{NiO}$ milled with carbon and methanol suggests another mechanism by which additives may steer sintered body microstructure, even past the additive desorption temperature. Specifically, when sintering is performed in an oxygen free atmosphere, desorption of carboncontaining species may drive surface reduction. This change in surface oxidation state introduces a metallic $\mathrm{Ni}$ species which facilitates rapid grain growth and decrease in porosity. The presence of such a mechanism suggests that the interplay between milling additive and sintering environment cannot be disregarded, even for high temperature sintering of $\mathrm{NiO}$.

\section{Acknowledgements}

The authors thank the N.Y.S. Graduate Research and Teaching Initiative (GRTI) for financial support. L. J. D. thanks the Air Force Summer Faculty Fellowship program for fellowship support. The authors thank the Advanced Imaging Facility of the College of Staten Island for SEM images, and Prof. William L'Amoreaux and Dr. Mike Bucaro for their help with SEM images.

Open Access: This article is distributed under the terms of the Creative Commons Attribution License which permits any use, distribution, and reproduction in any medium, provided the original author(s) and the source are credited.

\section{References}

[1] Adams TA, Nease J, Tucker D, et al. Energy conversion with solid oxide fuel cell systems: A review of concepts and outlooks for the short- and long-term. Ind Eng Chem Res 2013, 52: 3089-3111.
[2] Cowin PI, Petit CTG, Lan R, et al. Recent progress in the development of anode materials for solid oxide fuel cells. Adv Energ Mater 2011, 1: 314-332.

[3] Clemmer RMC, Corbin SF. The influence of pore and Ni morphology on the electrical conductivity of porous $\mathrm{Ni} / Y S Z$ composite anodes for use in solid oxide fuel cell applications. Solid State Ionics 2009, 180: 721-730.

[4] Guo W, Liu J. The effect of nickel oxide microstructure on the performance of Ni-YSZ anode-supported SOFCs. Solid State Ionics 2008, 179: 1516-1520.

[5] Itoh $\mathrm{H}$, Yamamoto T, Mori M, et al. Configurational and electrical behavior of $\mathrm{Ni}-\mathrm{YSZ}$ cermet with novel microstructure for solid oxide fuel cell anodes. J Electrochem Soc 1997, 144: 641-646.

[6] Wang Y, Walter ME, Sabolsky K, et al. Effects of powder sizes and reduction parameters on the strength of Ni-YSZ anodes. Solid State Ionics 2006, 177: 1517-1527.

[7] Jiang SP. Sintering behavior of $\mathrm{Ni} / \mathrm{Y}_{2} \mathrm{O}_{3}-\mathrm{ZrO}_{2}$ cermet electrodes of solid oxide fuel cells. J Mater Sci 2003, 38 : 3775-3782.

[8] Wilson JR, Barnett SA. Solid oxide fuel cell Ni-YSZ anodes: Effect of composition on microstructure and performance. Electrochem Solid-State Lett 2008, 11: B181-B185.

[9] Cho HJ, Choi GM. Effect of milling methods on performance of $\mathrm{Ni}-\mathrm{Y}_{2} \mathrm{O}_{3}$-stabilized $\mathrm{ZrO}_{2}$ anode for solid oxide fuel cell. J Power Sources 2008, 176: 96-101.

[10] Hong HS, Chae U-S, Choo S-T. The effect of ball milling parameters and $\mathrm{Ni}$ concentration on a YSZ-coated $\mathrm{Ni}$ composite for a high temperature electrolysis cathode. J Alloys Compd 2008, 449: 331-334.

[11] Restivo TAG, de Mello-Castanho SRH. Nickel-zirconia cermet processing by mechanical alloying for solid oxide fuel cell anodes. J Power Sources 2008, 185: 1262-1266.

[12] Tietz F, Dias FJ, Simwonis D, et al. Evaluation of commercial nickel oxide powders for components in solid oxide fuel cells. J Eur Ceram Soc 2000, 20: 1023-1034.

[13] Bowen P, Carry C. From powders to sintered pieces: Forming, transformations and sintering of nanostructured ceramic oxides. Powder Technol 2002, 128: 248-255.

[14] Chaim R, Levin M, Shlayer A, et al. Sintering and densification of nanocrystalline ceramic oxide powders: A review. Adv Appl Ceram 2008, 107: 159-169.

[15] Koch CC. The synthesis and structure of nanocrystalline materials produced by mechanical attrition: A review. Nanostruct Mater 1993, 2: 109-129.

[16] Jung S-H, Oh H-C, Kim J-H, et al. Pretreatment of zirconium diboride powder to improve densification. J Alloys Compd 2013, 548: 173-179.

[17] Castro RHR, Pereira GJ, Gouvêa D. Surface modification of $\mathrm{SnO}_{2}$ nanoparticles containing $\mathrm{Mg}$ or Fe: Effects on sintering. Appl Surf Sci 2007, 253: 4581-4585.

[18] Phung X, Groza J, Stach EA, et al. Surface characterization of metal nanoparticles. Mat Sci Eng A 2003, 359: 261-268.

[19] Burda C, Chen X, Narayanan R, et al. Chemistry and properties of nanocrystals of different shapes. Chem Rev 2005, 105: 1025-1102. 
[20] Eser O, Kurama S. The effect of the wet-milling process on sintering temperature and the amount of additive of SiAlON ceramics. Ceram Int 2010, 36: 1283-1288.

[21] Ivanov E, Suryanarayana C. Materials and process design through mechanochemical routes. J Mater Synth Proces 2000, 8: 235-244.

[22] Koch CC, Cho YS. Nanocrystals by high energy ball milling. Nanostruct Mater 1992, 1: 207-212.

[23] Zhang DL. Processing of advanced materials using high-energy mechanical milling. Prog Mater Sci 2004, 49: $537-560$.

[24] Lu K, Liang Y, Li W. Hindered sintering behaviors of titania nanoparticle-based materials. Mater Lett 2012, 89: 77-80.

[25] Faudot F, Gaffet E, Harmelin M. Identification by DSC and DTA of the oxygen and carbon contamination due to the use of ethanol during mechanical alloying of $\mathrm{Cu}-\mathrm{Fe}$ powders. J Mater Sci 1993, 28: 2669-2676.

[26] Peck MA, Langell MA. Comparison of nanoscaled and bulk NiO structural and environmental characteristics by XRD, XAFS, and XPS. Chem Mater 2012, 24: 4483-4490.

[27] Biesinger MC, Payne BP, Lau LWM, et al. X-ray photoelectron spectroscopic chemical state quantification of mixed nickel metal, oxide and hydroxide systems. Surf Interface Anal 2009, 41: 324-332.

[28] Barr TL, Seal S. Nature of the use of adventitious carbon as a binding energy standard. J Vac Sci Technol A 1995, 13: 1239-1246.

[29] Jang HD, Kim S-K, Kim S-J. Effect of particle size and phase composition of titanium dioxide nanoparticles on the photocatalytic properties. J Nanopart Res 2001, 3: 141-147.

[30] Sánchez LC, Arboleda JD, Saragovi C, et al. Magnetic and structural properties of pure hematite submitted to mechanical milling in air and ethanol. Physica B 2007, 389: 145-149.

[31] Spearing DR, Huang JY. Zircon synthesis via sintering of milled $\mathrm{SiO}_{2}$ and $\mathrm{ZrO}_{2}$. J Am Ceram Soc 1998, 81: 1964-1966.

[32] Zhou S, Chen H, Ding C, et al. Effectiveness of crystallitic carbon from coal as milling aid and for hydrogen storage during milling with magnesium. Fuel 2013, 109: 68-75.

[33] Huang ZG, Guo ZP, Calka A, et al. Effects of carbon black, graphite and carbon nanotube additives on hydrogen storage properties of magnesium. J Alloys Compd 2007, 427: 94-100.

[34] Richardson JT, Yiagas DI, Turk B, et al. Origin of superparamagnetism in nickel oxide. J Appl Phys 1991, 70: 6977.

[35] Gonçalves NS, Carvalho JA, Lima ZM, et al. Size-strain study of $\mathrm{NiO}$ nanoparticles by X-ray powder diffraction line broadening. Mater Lett 2012, 72: 36-38.

[36] Biesinger MC, Payne BP, Grosvenor AP, et al. Resolving surface chemical states in XPS analysis of first row transition metals, oxides and hydroxides: $\mathrm{Cr}, \mathrm{Mn}, \mathrm{Fe}, \mathrm{Co}$ and Ni. Appl Surf Sci 2011, 257: 2717-2730.

[37] Payne BP, Grosvenor AP, Biesinger MC, et al. Structure and growth of oxides on polycrystalline nickel surfaces. Surf Interface Anal 2007, 39: 582-592.

[38] McIntyre NS, Cook MG. X-ray photoelectron studies on some oxides and hydroxides of cobalt, nickel, and copper. Anal Chem 1975, 47: 2208-2213.

[39] Uhlenbrock S, Scharfschwerdt C, Neumann M, et al. The influence of defects on the Ni $2 \mathrm{p}$ and $\mathrm{O}$ 1s XPS of NiO. J Phys: Condens Matter 1992, 4: 7973.

[40] Payne BP, Biesinger MC, McIntyre NS. Use of oxygen/nickel ratios in the XPS characterisation of oxide phases on nickel metal and nickel alloy surfaces. J Electron Spectrosc Relat Phenom 2012, 185: 159-166.

[41] Jung J, Kim DL, Oh SH, et al. Stability enhancement of organic solar cells with solution-processed nickel oxide thin films as hole transport layers. Sol Energy Mater Sol Cells 2012, 102: 103-108.

[42] Rocha TCR, Oestereich A, Demidov DV, et al. The silver-oxygen system in catalysis: New insights by near ambient pressure X-ray photoelectron spectroscopy. Phys Chem Chem Phys 2012, 14: 4554-4564.

[43] Au CT, Hirsch W, Hirschwald W. Adsorption and interaction of methanol with zinc oxide: Single crystal faces and zinc oxide-copper catalyst surfaces studied by photoelectron spectroscopy (XPS and UPS). Surf Sci 1989, 221: 113-130.

[44] Deiner LJ, Serafin JG, Friend CM, et al. Insight into the partial oxidation of propene: The reactions of 2-propen-1-ol on clean and O-covered $\mathrm{Mo}(110) . \mathrm{J} \mathrm{Am}$ Chem Soc 2003, 125: 13252-13257.

[45] Iida Y. Sintering of high-purity nickel oxide. J Am Ceram Soc 1958, 41: 397-406.

[46] Arico E, Tabuti F, Fonseca FC, et al. Carbothermal reduction of the YSZ-NiO solid oxide fuel cell anode precursor by carbon-based materials. $J$ Therm Anal Calorim 2009, 97: 157-161.

[47] Haynes WN. CRC Handbook of Chemistry and Physics. Boca Raton, FL: CRC Press/Taylor and Francis, 2014.

[48] Natile MM, Glisenti A. Surface reactivity of NiO: Interaction with methanol. Chem Mater 2002, 14: 4895-4903.

[49] Shiau F-S, Fang T-T, Leu T-H. Effects of milling and particle size distribution on the sintering behavior and the evolution of the microstructure in sintering powder compacts. Mater Chem Phys 1998, 57: 33-40. 